\title{
EVALUATIVE CATEGORIES IN THE THEORY AND PRACTICE OF SUBSTANTIVE AND PROCEDURAL LAW
}

\author{
Petr P. Muraev \\ Volgograd State University, Volgograd, Russian Federation \\ Anna V. Milikova \\ Volgograd State University, Volgograd, Russian Federation
}

\begin{abstract}
Introduction: the paper is devoted to the study of problems associated with the use of "evaluative categories" in modern legal science and practice, as well as in law-making and law enforcement. The concept, essence, content of "evaluative categories", and their classification by various grounds are consistently revealed. The features of the use of "evaluative categories" in modern practice and the theory of substantive and procedural law are considered. The purpose of the research is to introduce in the scientific community the understanding of what should be understood by "evaluative categories", as well as to identify their importance in the theory and practice of substantive and procedural law. Methods: the methodological framework for the study is the universal dialectical method of scientific cognition, the principles of cognition of social phenomena based on the laws of dialectics, the logical methods of scientific cognition (analysis, synthesis, deduction, induction, abstraction), the special-legal methods (comparative, formal-legal), generalization, classification. Results: in the paper the approaches to the understanding of evaluative categories are identified, the essence is determined, and the variants of classification of evaluative categories in separate groups are proposed. Conclusions: it should be noted that evaluative categories have the properties of abstraction and act as a form of uncertainty in law; there is a need for their more consistent and accurate regulation.

Key words: evaluative categories, law, substantive law, procedural law, reliability, proportionality, reasonableness, good faith.
\end{abstract}

Citation. Muraev P.P., Milikova A.V. Evaluative Categories in the Theory and Practice of Substantive and Procedural Law. Legal Concept, 2019, vol. 18, no. 2, pp. 30-34. (in Russian). DOI: https://doi.org/10.15688/lc.jvolsu.2019.2.4

УДК 340.1

Дата поступления статьи: 02.03.2019

ББК 67.0

Дата принятия статьи: 23.03.2019

\section{ОЦЕНОЧНЫЕ КАТЕГОРИИ В ТЕОРИИ И ПРАКТИКЕ МАТЕРИАЛЬНОГО И ПРОЦЕССУАЛЬНОГО ПРАВА}

\author{
Петр Петрович Мураев \\ Волгоградский государственный университет, г. Волгоград, Российская Федерация \\ Анна Владимировна Миликова \\ Волгоградский государственный университет, г. Волгоград, Российская Федерация
}

Введение: статья посвящена исследованию проблем, связанных с использованием в современной юридической науке и практике, а также в правотворческой и правоприменительной деятельности оценочных категорий. Последовательно раскрывается понятие, сущность, содержание оценочных категорий, приводится их классификация по различным основаниям. Рассматриваются особенности использования оценочных категорий в современной практике и теории материального и процессуального права.

Цель исследования: внесение в научную среду понимания по поводу того, что следует считать «оценочными категориями», а также выявление их значимости в теории и практике материального и процессуального права. Методологическая основа работы: всеобщий диалектический метод научного познания, прин- 
ципы познания социальных явлений основанные на законах диалектики, логические методы научного познания (анализ, синтез, дедукция, индукция, абстрагирование), специально-юридические методы (компаративный, формально-юридический), обобщение, классификация. Результаты исследования: в рассматриваемой статье обозначены подходы к пониманию оценочных категорий, определена их сущность, а также предложены варианты классификации оценочных категорий в отдельных группах. Выводы: следует отметить, что оценочные категории обладают свойствами абстрактности и выступают в качестве формы неопределенности в праве, существует необходимость в более последовательной и точной их регламентации.

Ключевые слова: оценочные категории, право, материальное право, процессуальное право, достоверность, соразмерность, разумность, добросовестность.

Цитирование. Мураев П. П., Миликова А. В. Оценочные категории в теории и практике материального и процессуального права // Legal Concept = Правовая парадигма. - 2019. - T. 18, № 2. - C. 30-34. - DOI: https://doi. org/10.15688/lc.jvolsu.2019.2.4

\section{Введение}

Современный этап развития права в его объективном смысле и общества как базиса в целом обусловливает необходимость переосмысления существующих категорий, их особенностей и характерных черт, существующих в правовой доктрине. Появляется потребность в формировании новых научных подходов и теоретико-правовых взглядов на право как социальное явление. В этом контексте приобретают особое значение оценочные категории, поскольку они всячески пронизывают право, выявляют его содержание, определяют направленность правового регулирования и повышают регулятивный потенциал права. В современном действующем законодательстве все чаще встречаются такие оценочные категории, как: «разумность», «добросовестность», «обычно предъявляемые требования», «уважительная причина», 〈нуждаемость» и др. От того, насколько данные оценочные категории укоренятся в правосознании правоприменителя и законодателя, проникнут в правовую культуру населения в целом, зависит и эффективность права как социального регулятора. Именно поэтому необходимо выяснить понятие оценочных категорий, выявить их сущность, а также классифицировать по различным возможным основаниям, рассмотреть их в теории и практике материального и процессуального права.

\section{Современные подходы \\ к пониманию оценочных категорий и их классификации для целей материального и процессуального права}

В настоящее время наблюдается плюрализм подходов к пониманию оценочных ка- тегорий. Каждый из исследователей определяет их правовую природу и сущность, исходя из целей и предназначения тех или иных категорий в правовом регулировании общественных отношений. Так, в теории права и науке юридической техники оценочные категории рассматривают как разновидность технико-юридических средств и приемов [7, с. 658].

C.В. Петраков отмечает, что оценочные категории представляют собой специфическую форму, смысл которой «опредмечивается в рамках конкретной фактической ситуации, сложившейся по делу (случая)» [2, с. 256].

Как верно заметил Я.М. Брайнин, оценочные категории «уточняются при применении закона» $[1$, с. 134]. То есть изначально все оценочные категории носят абстрактный характер, и в них отсутствует необходимая степень конкретизации и точности, они объективно требуют восполнения их изначальной неопределенности. Поэтому в процессе правоприменительной деятельности с учетом правовых познаний и правовой культуры субъекта правоприменения происходит восполнение неопределенности оценочной категории и придание ей должной степени конкретизации и точности.

Суммируя все вышеизложенное, можно сказать, что оценочные категории - это разновидность технико-юридических средств и приемов, представляющих собой специфические формы выражения неопределенности в праве, конечный смысл и содержание которых определяются с учетом правосознания субъекта правоприменения в рамках обстоятельств конкретного дела.

Многообразие существующих в современной теории и практике материального и процессуального права оценочных категорий 
требует их некоторого упорядочивания, то есть расположения по определенным классификационным группам в соответствии с их значимыми признаками. Так, А.С. Рясина предлагает классифицировать оценочные категории по следующим основаниям:

1) в зависимости от отраслевой принадлежности: оценочные категории гражданского права, оценочные категории уголовного права, оценочные категории уголовного процесса и др.;

2) в зависимости от элемента нормы права, их содержащего: оценочные категории, которые содержатся в диспозиции («добросовестно» - ст. 41 АПК РФ); оценочные категории, которые содержатся в гипотезе («достаточные основания» - ст. 1044 ГК РФ); оценочные категории, которые содержатся в санкции;

3) если давать им оценку с позиций легитимности и юридической значимости актов толкования оценочных категорий: оценочные категории, которые имеют официальное толкование; судебное и административное; оценочные категории, которые имеют доктринальное толкование; обывательское толкование [6, с. 29-31].

\section{Практические особенности}

\section{применения оценочных категорий} в материальном и процессуальном праве

В настоящее время оценочные категории приобретают особо важное значение в сфере властной реализации права. Большое внимание оценочным категориям приходится уделять судам, когда их использование необходимо для вынесения правильного, обоснованного, законного и справедливого решения. Более того, рассмотрение и уяснение содержания оценочных категорий также осуществляется и в процессе доказывания при судебном разбирательстве при установлении юридически значимых обстоятельств дела и иных имеющих значение для разрешения дела обстоятельств. Широкое применение оценочных категорий в правоприменительной практике стало предпосылкой для выработки многообразных позиций судов, посвященных практической реализации оценочных категорий.

Так, например, особенности такой оценочной категории, как «степень физических и нравственных страданий», проявляются в том, что ее конкретизация должна осуществляться «с учетом фактических обстоятельств причинения морального вреда, индивидуальных особенностей потерпевшего и других конкретных обстоятельств, свидетельствующих о тяжести перенесенных им страданий», при этом также должны учитываться требования «разумности и справедливости» [4].

«Достоверность рекламы» как оценочная категория и особенности определения достоверности раскрываются в Постановлении Пленума ВАС РФ от 8 октября 2012 г. № 58 «О некоторых вопросах практики применения арбитражными судами Федерального закона “О рекламе"» [3].

Стоит отметить, что информация, которая содержится в рекламе, должна отвечать критериям достоверности, чтобы сформировать у потребителя истинное представление о товаре или услуге, его качестве, потребительских свойствах, при этом «...оценка такой рекламы осуществляется с позиции обычного потребителя, не обладающего специальными знаниями» [3].

«Соразмерность» как оценочная категория применительно к мерам по обеспечению иска «предполагает принятие во внимание характера допущенных нарушений, а также негативных последствий, которые может повлечь применение таких мер».

Применительно к «малозначительности» деяния по преступлениям экстремистской направленности необходимо «учитывать, в частности, размер и состав аудитории, которой соответствующая информация была доступна, количество просмотров информации, влияние размещенной информации на поведение лиц, составляющих данную аудиторию» [5].

\section{Заключение}

В рамках данной работы были рассмотрены подходы к пониманию оценочных категорий, выявлена их сущность, предприняты попытки классификации оценочных категорий по различных группам. Кроме того, рассмотрены решения судов, которые в некоторой степени детализируют и конкретизируют содержание оценочных категорий. 
Подводя итог, следует отметить, что оценочные категории обладают свойствами абстрактности, неконкретизированности, выступают в качестве формы неопределенности в праве. С учетом тенденции увеличения в объективном праве числа оценочных категорий возникает необходимость более последовательной и точной их регламентации как в правовой науке, так и в судебной практике, поскольку чем больше в норме права оценочных формулировок, тем менее определено содержание самой нормы в тексте нормативно-правового акта, а потому увеличение числа оценочных элементов без должной их конкретизации может создавать основу для злоупотреблений при правоустановлении и правоприменении.

\section{СПИСОК ЛИТЕРАТУРЫ}

1. Кудрявцев, В. Н. Общая теория квалификации преступлений / В. Н. Кудрявцев. - М., 1972. -352 c.

2. Петраков, С. В. Правила использования оценочных категорий в правовом регулировании / С. В. Петраков // Юридическая техника. - 2009. № 3. - C. $255-263$.

3. Постановление Пленума ВАС РФ от 08.10.2012 № 58 «О некоторых вопросах практики применения арбитражными судами Федерального закона “О рекламе”». - Электрон. текстовые дан. Режим доступа: http://www.consultant.ru/cons/cgi/ online.cgi? $\mathrm{req}=$ doc $\&$ base $=$ LAW $\& \mathrm{n}=137349 \&$ fld $=$ $134 \& \mathrm{dst}=1000000001,0 \& \mathrm{rnd}=0.7001595608649047 \#$ 020939169491164922 (дата обращения: 15.03.2019).

4. Постановление Пленума Верховного Суда РФ от 20.12.1994 № 10 (ред. от 06.02.2007) «Некоторые вопросы применения законодательства о компенсации морального вреда». - Электрон. текстовые дан. - Режим доступа: http://www. consultant.ru/ cons $/$ cgi $/$ online cgi?req $=$ doc\&base $=\mathrm{LAW} \& \mathrm{n}=66230$ $\&$ fld $=134 \& \mathrm{dst}=1000000001,0 \& \mathrm{rnd}=0.66677996$ 11542058\#07389043923838281 (дата обращения: 16.03.2019). - Загл. с экрана.

5. Постановление Пленума Верховного Суда РФ от 28.06.2011 № 11 «О судебной практике по уголовным делам о преступлениях экстремистской направленности» (ред. от 20.09.2018). - Электрон. текстовые дан. - Режим доступа: http://www. consultant. $\mathrm{ru} /$ cons/cgi/online.cgi?req $=$ doc\&ts $=3120768850554$ $5195487895842 \&$ cacheid $=2$ D 89 C 821 FE 57 CD 29
CEFB9D2A03F4FEF4\&mode $=$ splus $\&$ base $=$ LAW $\& n=$ 307176\&rnd $=0.3497091626856941 \# 10112 \operatorname{edg} 20 x$ (дата обращения: 16.03.2019).

6. Рясина, А. С. Виды оценочных категорий / А. С. Рясина // Актуальные проблемы современности: наука и общество - 2016. - № 1. - С. 29-31.

7. Рясина, А. С. Оценочные категории как прием законодательной техники в российском праве / А. С. Рясина // Юридическая техника. - 2015. № 9. - C. 658-665.

\section{REFERENCES}

1. Kudryavtsev V.N. General Theory of Qualification of Crimes. Moscow, 1972. 352 p. (in Russian).

2. Petrakov S.V. Rules for the Use of Evaluation Categories in Legal Regulation. Legal technique, 2009, no. 3, pp. 255-263. (in Russian).

3. Resolution of Plenum of SAC of the Russian Federation of 08.10.2012 No. 58 "About some questions of practice of arbitration courts of the Federal law "On advertizing". URL: http://www. consultant.ru/cons/cgi/online.cgi?req $=$ doc $\&$ base $=$ LAW $\& n=137349 \&$ fld $=134 \& d s t=1000000001,0$ \&rnd $=0.7001595608649047 \# 020939169491164922$ (accessed 15 March 2019). (in Russian).

4. Resolution of Plenum of the Supreme Court of the Russian Federation of 20.12.1994 No. 10 (edition of 06.02.2007) "Some questions of application of the legislation on compensation of moral harm". URL: http://www.consultant.ru/cons/ cgi/online.cgi?req $=$ doc $\&$ base $=$ LAW $\& n=66230$ $\& \mathrm{fld}=134 \& \mathrm{dst}=1000000001,0 \& \mathrm{rnd}=0.66677$ 99611542058\#07389043923838281 (accessed 16 March). (in Russian).

5. Resolution of Plenum of the Supreme Court of the Russian Federation of 28.06.2011 No. 11 "About Judicial Practice on Criminal Cases about Crimes of Extremist Orientation". URL: http://www. consultant.ru/cons/cgi/online.cgi?req $=$ doc\&ts $=$ 31207688505545195487895842 \& cacheid $=2$ D89 C821FE57CD29CEFB9D2A03F4FE F4\& mode $=$ splus \& base $=$ LAW\& $=307176 \& \mathrm{rnd}=0.3497091626856941 \#$ 10112edg20x. (accessed 16 March). (in Russian).

6. Ryasina A.S. Types of Evaluation Categories. Actual Problems of Modernity: Science and Society, 2016, no. 1, pp. 29-31. (in Russian).

7. Ryasina A.S. Evaluation Categories as the Reception of Legislative Technique in Russian Law. Legal technique, 2015, no. 9, pp. 658-665. (in Russian). 


\section{Information about the Authors}

Petr P. Muraev, Candidate of Sciences (Jurisprudence), Associate Professor, Department of Criminal Procedure and Criminalistics, Volgograd State University, Prosp. Universitetsky, 100, 400062 Volgograd, Russian Federation, petr.muraev@mail.ru, https://orcid.org/0000-0002-4181-7098

Anna V. Milikova, Senior Lecturer, Department of Criminal Procedure and Criminalistics, Volgograd State University, Prosp. Universitetsky, 100, 400062 Volgograd, Russian Federation, milikova_av@mail.ru, https://orcid.org/0000-0002-0341-4634

\section{Информация об авторах}

Петр Петрович Мураев, кандидат юридических наук, доцент кафедры уголовного процесса и криминалистики института права, Волгоградский государственный университет, просп. Университетский, 100, 400062 г. Волгоград, Российская Федерация, petr.muraev@mail.ru, https://orcid.org/ 0000-0002-4181-7098

Анна Владимировна Миликова, старший преподаватель кафедры уголовного процесса и криминалистики института права, Волгоградский государственный университет, просп. Университетский, 100, 400062 г. Волгоград, Российская Федерация, milikova_av@mail.ru, https:/orcid.org/ 0000-0002-0341-4634 